\title{
THE CONDITIONS AND OPPORTUNITIES FOR TEACHERS' PROFESSIONAL ADAPTATION AND CAREER IN SCHOOLS OF LATVIA AND LITHUANIA
}

\author{
Julija Melnikova \\ Klaipeda University, Lithuania \\ Jeḷena Zaščerinska \\ Centre for Education and Innovation Research, Latvia
}

\begin{abstract}
The article highlights the modern notion of career and explores the salient factors, influencing teachers' professional development and career opportunities in today's secondary schools in Latvia and Lithuania. The implications of empirical research on the peculiarities of teachers' as young specialists' adaptation and it influencing factors are presented. The contradictory views on the problems of professional adaptation, expressed by two groups of respondents - school heads and young specialists - are analyzed. The article examines opinion of teachers, who have different work experience and professional category, on the topic of career development opportunities. The article also presents the empirical evidence on the question: what is the role of school heads (principal and deputy heads) in the aspect of optimization of teachers' professional career. Moreover, the recommendations for high schools on how to optimize the teaching-learning process in order to ensure successful start of teachers' pedagogical career are provided.
\end{abstract}

Keywords: Adaptation, career, optimization, professional career development, secondary schools, teacher, young specialist.

\section{Introduction}

Increasing competition on the labor market as the result of economic instability and dynamic environment influence the career of young specialists and put forward new requirements for professional development. That is why today it is important to talk not only about specific professional knowledge, skills or experience, necessary in postmodernist society, but, in general, about highlyqualified citizens that are able to work in an intensively changing world. That is very important for Latvia and Lithuania, who have the similar historical background, transition period and traditions in education, and are currently seeking to re-arrange their educational systems. The interest in young specialists' professional development intensified the effort not only to analyze the problems of professional training, but also to highlight the aspects of preparation for career 
and to clarify, what kind of assistance should be provided at the beginning of personal career development in Latvia and Lithuania's educational systems.

The word career takes its roots from the French word carriere, which means a sphere of activity, profession. There are various conceptions of career. The Dictionary of International Words discloses the meaning of the word career and provides a number of definitions: a successful activity, success in life, kind of activity. Career means the goals of a person, the union of person's convictions and activities reflected in a life-long work experience. Gumuliauskienè and Augiene (2002), analyzing the notion of career, emphasize the importance of person 's improvement in a selected sphere of activity what is positively evaluated by society. Emerging from above analyzed definitions, two aspects in the career conception understanding may be extracted. On the one hand, career may be understood in a broad mind as the life-long planning and realizing of its goals, on the other - career is understood as employment on the basis of acquired profession. Those who support the second point of view usually use the term professional career, thus emphasizing the importance of employment in the notion of career.

According to Stanišauskienè and Večkienè (1999), there exist two career models in person's activity. They are bureaucratic career model and modern career model. The modern career model has recently become dominant in person 's activity, and is of a special importance to teachers' as young specialists' career development. Bureaucratic career model stresses the achievement of individual goals like social status; pay etc., in certain terms in comparison with other individuals, while the modern career model emphasizes the satisfaction of self-realization and success demands, what is especially important in pedagogical work. So, taking in mind the dominant modern career model, the teacher's career may be determined not only as hierarchical career path in terms of an organization, but more focused on competencies, self-realization, and satisfaction of success demands. These provide an opportunity for every school teacher to build a career independently from organization hierarchical structure and career path.

Professional career and recognition depends not only on an employee, his personal features, education, communication skills etc., it usually depends on various conditions and circumstances. It 's an employer, who can ensure, that the employee is satisfied with the work conditions. It is worth to mention, that the first work experience may influence the self-assurance. However, an employer can positively influence the career. Here the problem of appreciation of work true value is of a crucial importance. The employer has to evaluate the employee, to disclose all advantages and disadvantages that may possibly affect his career. The employee, in his turn, is tend to be more realistic in assessing his own possibilities if he is responsible for more and more complex procedures and is acknowledged with work perspectives. 
Latvian and Lithuanian scientists Olechnovica and Kravale-Paulina (2008), Jucevičienè and Lepaitè (2000); Stanišauskienè and Večkienè (2000) and others have investigated the issues of career, career development, preparation for career, the importance of personal qualities on career development. However, the issue of secondary school teachers'career development has been examined less. Teachers as young specialists' adaptation peculiarities and their career opportunities in today's secondary schools of Latvia and Lithuania have not been analyzed.

The aim of the research: To analyze the adaptation of young specialists who work at schools, their career opportunities and career influential factors, providing optimization strategy for today's secondary school.

\section{The objectives of the research:}

1. To disclose the peculiarities of teachers' as young specialists' adaptation and distinguish opportunities for optimization;

2. To highlight the factors that influence the development of profession career;

3. To analyze the career opportunities in today 's secondary schools;

4. To disclose the role of a school heads (principal and deputy heads) in optimization of teachers career.

\section{The method of the research:}

The analysis of scientific literature, anonymous survey in writing; content analysis, case analysis, statistical analysis of empirical data.

\section{The methods and organization of the research}

The quantitative research involved three groups of respondents working at secondary schools of Latvia and Lithuania: 103 young specialists (length of service from 1 to 3 years), 168 secondary school teachers-methodologists (length of service more then 3 years) and 15 secondary school heads. One group of respondents, consisted of 14 teachers methodologists (the length of service was not considered), participated in the qualitative research. The total number of respondents that took part in the research was 300. The survey took place in the secondary schools of Klaipeda district and Riga district in 2016.

Therefore research was divided into four stages. During the first stage the survey was conducted among teachers as young specialists. During the second stage the school principals and deputy heads were questioned. The questionnaires for both groups of respondents were similar. This provided a possibility to analyze the problem of adaptation and career development from different points of view: on the one hand young specialists as employees, who are directly involved in adaptation process and on the other - school heads that influence the process of adaptation and are responsible for it. The questionnaire included 20 questions of different types (open and closed). It was intended to state: which factors do influence young specialists adaptation when they start working at secondary 
schools; which factors complicate the process of adaptation for young specialists; how young specialists evaluate their competencies and personal readiness to work at schools; what methodic help they get from colleagues, school administration; how should high schools organize studies in order to make the adaptation process easier; how young specialists evaluate their career opportunities in today's secondary schools; which factors influence successful career development.

Teachers-methodologists, whose length of service was more then 3 years took part in the third stage of the research. With the help of the questionnaire, consisted of 20 questions, it was aimed to highlight the aspects of cooperation between secondary schools' teachers and young specialists, to examine existing cooperation culture and factors, that could ensure the successful adaptation of young specialists.

The fourth stage was dedicated to case analysis. Teachers with the degree of methodologists participated at this stage. It was intended to highlight: what are the peculiarities of teachers-methodologists ' career development; what occasions or circumstances influenced teachers to acquire methodologists' degree; who provided help and assistance in acquiring the degree; which personal qualities and competencies are important for professional development; what should young specialists have in mind in order to ensure the successful career development.

The data collected was weighted using statistical programming SPSS. Depending on data specifics different statistical methods were applied: hypotheses were checked using ANOVA, the average and percentage meanings were counted, interconnection between, variables was checked using Spearmen correlation coefficient.

\section{Research data analysis}

\section{The peculiarities of teachers as young specialists' adaptation and the factors influencing the process of adaptation}

The results of data analysis show, that expectations about work at school of more then a half of young specialists in Latvia $(50,2 \%)$ and Lithuania $(58,4 \%)$, who took part in the survey, have justified only partly. In young specialists opinion, the problems occur because of different factors that make influence on the process of adaptation ( $\mathrm{r}=0,4 ; \mathrm{p}=0,0001 ; \mathrm{r}=0,6 ; \mathrm{p}=0.0001$ respectively). The factors mentioned by teachers in both groups, whose expectations haven 't come true, were: the lack of pedagogical experience, the lack of methodology knowledge, the problems with students' discipline during lessons, overloaded schedule. So, we can presuppose that unjustified expectations of young specialists while starting work at schools are mainly caused by experienced failures or difficulties in organizing the teaching process. Such factors as little salary, insufficient collaboration with colleagues, lack of attention from colleagues' side, 
school environment and school culture are of less importance in the aspect of adaptation.

The data analyzed shows that the majority of young specialists $(88,3 \%)$ in Latvia and $(94,26 \%)$ in Lithuania have adapted at their work places during the first year of work. The respondents were given the list of factors that have an influence on adaptation process and were asked to distribute them according to their importance.

\section{The most important factors are (respectively in Latvia and Lithuania):}

- $\quad$ Motivation to work at school $(\bar{X}=7,52 ; \bar{X}=8,12)$;

- $\quad$ Professional competence acquired at high schools $(\bar{X}=6,81 ; \bar{X}=7,11)$;

- $\quad$ The young specialist's personal qualities $(\bar{X}=6,80 ; \bar{X}=6,94)$;

- Cooperation with the colleagues $(\bar{X}=4,63 ; \bar{X}=5,12)$.

The factors of less importance are:

- $\quad$ Psychological climate at school $(\bar{X}=2,53 ; \bar{X}=3,14)$;

- $\quad$ Financial conditions $(\bar{X}=3,85 ; \bar{X}=4,10)$;

- Social guarantees - salary, apartment, etc. $(\bar{X}=3,93 ; \bar{X}=4,23)$.

The same respondents had to distribute the factors that hinder the process of adaptation in schools. The results show that the salient factors that complicate the process of adaptation are (respectively in Latvia and Lithuania):

- $\quad$ The lack of pedagogical experience $(\bar{X}=3,21 ; \bar{X}=4,10)$;

- The teachers' obligation to keep documents $(\bar{X}=3,54 ; \bar{X}=4,24)$;

- $\quad$ The lack of attention towards young specialists needs $(\bar{X}=4,54$; $\bar{X}=4,64)$.

The adaptation of young specialists in schools depends on assistance they get when starting to work. We were interested in what kind of methodic assistance young specialists usually get from experienced colleagues. It was found out that the usual help is: how to asses the students ' academic achievements; how to organize the teaching process; share necessary materials, handouts; open lessons, organized by experienced colleagues; assistance in preparing curriculum plans. Though, it's only one third of respondents $(29,0 \% ; 34,0 \%$ respectively) who would expect experienced colleagues at their lessons and would ask for a feedback about lesson activities. Even less number of respondents (21\%; 24,3\% respectively) would get necessary assistance in preparation for the lessons.

We inquired about how the respondents evaluate the assistance they get, and what kind of assistance they really need. It has become clear that the majority $(64,5 \% ; 72,3 \%$ respectively) of respondents, participated in the research, evaluate the assistance they get as ,,very good“" or „good“. The majority of young specialists in Latvia pointed, that the necessary assistance would be: Advice on how to organize work with parents $(76,3 \%)$; advice on how to keep discipline during the lessons $(58,6 \%)$; assistance in preparation for the lessons $(62,3 \%)$. 
Quite a numerous group of respondents in Lithuania wishes that: colleagues visited their lessons $(58 \%)$, but at the same time they worry about mistakes which may influence their further career. (E.g. "The principal or deputy heads will be informed about my mistakes." "The visits may call out a negative feedback." "School community may get aware of my failures.").

In order to support and develop collaboration between young specialists and experienced teachers it was suggested by young specialists: to organize methodic meetings, where experienced colleagues would share their good practice $(65,7 \%$; $68,2 \%$ respectively); to organize frequently open lessons $(55,2 \% ; 59,6 \%$ respectively); to get necessary support and initiative from school heads (51,9\%; $49,8 \%$ respectively).

\section{Colleagues' assistance}

- Open lessons organized by experienced colleagues

- Benevolent visits of experienced teacher to lessons of young specialists, analysis of lessons and constructive advice on lessons' improvement

- Assistance and consulting in preparing visual teaching materials

- Methodic help in preparing for the lessons

- Consulting on compiling curriculum plans and completing school documentary

- Exchanging the experience on communication and cooperation with students' parents

- Consulting on organization of after-lesson activity

- Exchanging the experience on the aspects of work of class leader

- Assistance in developing management competencies (in order to improve the organization of a lesion, etc)

- Cooperation in solving the behavioural problems of pupils

\section{School heads' ${ }^{6}$ assistance}

- Formation of positive view on young specialists in teachers ' community

- Formation and maintaining cooperation culture and positive psychological climate in teachers" community

- Reinforcing and maintaining young specialists" motivation to work in schools

- Organization of systematical individual conversations between school heads and young specialists

- Appointment of a person who is responsible for providing assistance to young specialists

\section{$\uparrow$}

Factors interconnected with teacher's as young specialist's personality

- Initiative and willingness of a young specialist to cooperate with colleagues

- Positive motivation to work in schools

- Adequate self-evaluation

- Personal traits: responsible, reliable, benevolent, etc.

Figure 1 The framework of successful adaptation in schools 
However, school heads, in their turn, discussing collaboration problems, emphasized the young specialists' initiative but haven 't mentioned their own role in cooperation process.

The research disclosed differences in the opinion considering career development between various groups of respondents. Young specialists emphasized the importance of professional preparation and while teachersmethodologists put an accent on personal qualities, such as persistence, willpower, self-confidence, initiative, responsibility, dutifulness, and flexibility.

After having analyzed the opinion of young specialists that took part in the research we can build the model of successful adaptation in schools (1 fig.).

\section{The factors influencing successful teacher's career development}

According to the young specialists' opinion, the acquisition of higher pedagogical degree depends on (respectively in Latvia and Lithuania): professional preparation $(\bar{X}=5,58 ; \bar{X}=5,94)$; communication and collaboration skills $(\bar{X}=5,23 ; \bar{X}=4,98)$; adequate self-assessment $(\bar{X}=5,16 ; \bar{X}=5,38)$; selfconfidence, self-assurance $(\bar{X}=4,82 ; \bar{X}=4,94)$; tolerance $(\bar{X}=4,63 ; \bar{X}=4,20)$. The school heads' opinion on the topic is quite different. School heads put an accent on these factors, which, to their mind, influence teachers' career development: ability to analyze pedagogical activity; ability to take right solutions in different pedagogical situations; organizational skills; ability to think critically. The respondents have tallied with opinions only in the aspect of communication and cooperation among teachers, students and their parents as the one of most important to teachers' career.

In order to analyze the peculiarities of teachers' career, the qualitative research (case analysis) was conducted. Teachers-methodologists took part in it. Teachers both in Latvia and Lithuania estimated their personal qualities as salient for career development. These qualities are: persistence ("...though the first year period was very difficult, I have never lost hope, just thought sometimes that I should change something in my own actions...”) will-power (“...in order to prepare a report and take part in a conference I had to analyze a huge amount of literature, though I feel myself better in practical activity..."), self-confidence ("I have always known that I am able to achieve more"), initiative ("I was a leader of different school events that have become traditional"), responsibility ("I have always been preparing for the lessons, so that they were interesting for the students", "School Heads consider me a highly responsible person, so I often represent my institution"), dutifulness ("Since my first year at school I have been strongly responsible for my activity, especially for checking students' papers and preparing for the lessons") and flexibility ("Even though I prefer definite planning, it happens so, that it is necessary to change according to situation, so I 
am ready to do it", "Changes provoke difficulties but I understand that sometimes it is important to change..."), ability to communicate and cooperate ("The ability to communicate and cooperate with students and their parents for some degree affects the success of pedagogical work"). While analyzing research data there were noticed some similarities in teachers 'career development. Teachers were focused on:

- $\quad$ expansion of competencies;

- improvement of qualification skills in the context of lifelong learning;

- further career planning: they used to estimate circumstances and take rational decisions about career development, they managed to plan and forecast career development and took part in this process;

- attention to cooperation with colleagues: initiated cooperation and collaboration processes in school community.

Also it could be mentioned similar circumstances that had a positive influence on teachers-methodologists' career development:

- $\quad$ Supportive organizational environment (E.g. When I was seeking my goals I always met support and encouragement from colleagues and school heads.);

- $\quad$ Support from superior institutions (E.g. When I got a proposal from local Education Department considering my career, I felt more selfconfident, and that was one of the main reasons for me to move forward in my career.).

The research disclosed differences in the opinion considering career development between various groups of respondents. Young specialists emphasized the importance of professional preparation and while teachersmethodologists put an accent on personal qualities, such as persistence, willpower, self-confidence, initiative, responsibility, dutifulness, and flexibility. Moreover, research results prove that success in career depends on planning, lifelong learning and qualification improvement. Teachers-methodologists, unlike the young specialists, turned attention on the importance of encouragement and support from superior organizations. They also stressed the necessity of cooperation and collaboration. School heads named several important factors crucial for pedagogic career, eminent among them were ability to analyze pedagogic activity, ability to take right decisions, organizational skills and class management skills, ability to construct cooperative relations (table 1). 
Proceedings of the International Scientific Conference. Volume II, May $26^{\text {th }}-27^{\text {th }}$, 2017. 479-492

Table 1 The opinion of different groups of respondents on the most important factors, influencing teachers' ${ }^{6}$ as young specialists ${ }^{6}$ professional career development

\begin{tabular}{|c|c|c|}
\hline $\begin{array}{c}\text { Teachers as young } \\
\text { specialists }\end{array}$ & Teachers-methodologists & School Heads \\
\hline $\begin{array}{l}\text { - Professional } \\
\text { preparation and } \\
\text { pedagogical } \\
\text { competencies } \\
\text { - Adequate self- } \\
\text { assessment } \\
\text { - Self-confidence }\end{array}$ & $\begin{array}{l}\text { - Personal traits: persistence, will- } \\
\text { power, self-confidence, } \\
\text { initiative, responsibility, } \\
\text { dutifulness, and flexibility } \\
\text { - Lifelong learning and } \\
\text { qualification improvement } \\
\text { - Career planning } \\
\text { - Comfortable work environment } \\
\text { - Encouragement and support } \\
\text { from superior organizations } \\
\text { - Necessity of cooperation and } \\
\text { collaboration }\end{array}$ & $\begin{array}{l}\text { - Pedagogical skills and } \\
\text { abilities } \\
\text { - Critical thinking skills } \\
\text { - Management } \\
\text { competencies } \\
\text { - Creativity }\end{array}$ \\
\hline
\end{tabular}

\section{Young specialists career opportunities in today's Latvian and} Lithuanian secondary schools

Respondents were asked to evaluate young specialists career opportunities in today's secondary schools using 5-grade scale.

Approximately half of respondents in Latvia evaluated young specialists pedagogical career opportunities as average $(54,24 \%)$, one third of respondents $(29,25 \%)$ - as low. The edge positions were chosen by 16, 56 percent of respondents. 6, 23 percent of respondents pointed on very high career opportunities, while 10, 32 percent of respondent evaluated career opportunities as very low. In Lithuania the majority of respondents $(72,43 \%)$ evaluated career perspectives as average.

According to the respondents' opinion (in Latvia and Lithuania respectively), the factors that hinder the career of young specialists are:

- $\quad$ The lack of initiative from their side $(46,23 \% ; 34,28 \%)$;

- $\quad$ The lack of motivation $(39,52 \% ; 48,50 \%)$;

- $\quad$ Competition among pedagogues in schools $(38,28 \% ; 34,12 \%)$;

- The lack of attention, support, assistant from school heads side $(33,22$ $\% ; 42,12 \%)$;

- Mistrust and non-benevolent attitude towards young specialists and their activities $(28,16 \% ; 22,18 \%)$;

- Superficial attitude towards work and responsibilities from young specialists side $(26,41 \% ; 18 / 16 \%)$. 
The comparison of results in various groups of respondents showed, that young specialists mostly mentioned school environment - colleagues, school heads, competition between teachers, but almost nobody mused upon personal qualities and ambitions. Elder colleagues, teachers-methodologists and school heads turned attention on young specialists' passiveness and lack of responsibility considering pedagogic career (E.g. They never show that they are interested in projects or social activity. They don't want to take part in methodic meetings.).

On the basis of empirical evidence we may presuppose, that opportunities for career in secondary schools both in Latvia and Lithuania are average. Young specialists consider it as the result of today's school environment, insufficient assistance from experienced colleagues and school heads side. According to school heads' and teachers-methodologists' opinion, young specialists are unable to enjoy the career opportunities through their own fault.

\section{The role of school heads in teacher's career development}

We revealed teachers-methodologists' and young specialists' opinions on this topic and it is worth to mention that young specialists were much more active then their elder colleagues expressing their points of view. So we may presuppose that career problems are more urgent to young specialists then to elder school personnel. Summarizing research results in all groups of respondents both in Latvia and Lithuania these main principal's responsibilities may be extracted:

- School principal should initiate and encourage teachers" career development and support their motivation;

- School principal, who is interested in teachers ' career, should posses personal qualities, such as tolerance, benevolence, optimism and innovators, respect towards colleagues, ability to communicate and cooperate;

- School principal should ground school management on the democratic principles;

- School principal should create a positive psychological school climate;

- $\quad$ School principal should stimulate the positive attitude towards young specialists;

- School principal should search for methods to diminish competence among teachers;

- $\quad$ School principal should stimulate young specialists to plan their career and provide them necessary support on every level.

We also tried to attain what school principals should change in school processes and procedures in order to facilitate the adaptation of young specialists. Content analysis provided possibility to extract main categories that generalize distinguishing features of work with young specialists: 
- To provide necessary information about school culture, discuss work conditions, main responsibilities, rights and obligations.

- $\quad$ During the first year not to overload the schedule;

- To provide possibility to work with lower classes in order to avoid pedagogical problems;

- $\quad$ To appoint a tutor, who would provide necessary assistant and help;

- $\quad$ During the first year it isn't recommended to appoint a young specialist on the duties of class master. Instead, young specialists could be asked to assist an experienced class master, thus providing possibilities to learn from a good practice.

- To arrange consultations with experienced colleagues where different pedagogical problems could be discussed.

The research conducted in secondary schools of Latvia and Lithuania showed that there isn 't used any actual strategy on how to assist young specialists at the beginning of their career. All the respondents were common in their opinion about the importance of school heads role in the teachers' career development. The data analyzed gives a basis to state, that school principal should be responsible for creating conditions for successful teachers', and especially young specialists' career development. Principal should support and encourage young specialists 'initiatives. It is of a special importance to provide opportunities for young specialists to acquire work experience, self-assurance, assist in overcoming obstacles and provide possibilities to develop professionally and personally.

\section{The preconditions of optimization the pedagogical studies in high schools of Latvia and Lithuania}

The respondents were asked to answer the open question about how they would organize the studies in high schools in order to make easier the start of career. The method of content analysis gave a possibility to extract two categories that reflect respondents' points of view on research topic about theoretical and practical preparation.

Both Latvian and Lithuanian respondents stressed the importance of theoretical preparation and necessity of its optimization. The majority of respondents in Latvia $(68,24 \%)$ pointed, that high schools should provide psychology course for future teachers, where of a major importance would be communication psychology, children and teenagers psychology. More then a half of the respondents in Lithuania (54,56\%) emphasized the importance of pedagogy studies and wished to have deeper methodic knowledge. Both Latvian and Lithuanian teachers young specialists when starting work at schools feel the lack of theoretical knowledge in the fields of: 
- creativity upbringing,

- upbringing of critical thinking,

- $\quad$ bringing up children with special educational needs;

- discipline problems;

- project activity;

- $\quad$ organizing of meetings with parents;

It would be useful, to respondents' mind, to get acknowledged with class masters responsibilities, get a course on how to organize classroom activities and after-classes activities. Teachers in Latvia mentioned, that young specialists are usually aware only about traditional methods of teaching, while the untraditional methodology and modern pedagogical technologies are less known.

Lithuanian respondents, participated in the research, emphasized the necessity of practical preparation of young specialists. They advised to extend the terms of pedagogical practice, ("...it should last for a year at least..."), students should get an opportunity to conduct lessons by themselves ("... it would be useful for students to conduct lessons by themselves at once..."), it is purposeful, according to respondents, to observe lessons, conducted by experienced colleagues. It was also offered to organize pedagogical practice in schools subordinated to high schools where usually work highly-qualified teachers.

The research results show that young specialists both in Latvia and Lithuania feel the lack of theoretical preparation: pedagogy and psychology knowledge, practical experience. High schools students as future pedagogues should have an opportunity to get acquainted with class masters responsibilities and learn how to organize after-classes activities. Moreover, it would be useful to extend the terms of pedagogical practice and provide high-qualified assistance during the practice.

\section{The implementations of the research}

1. The research conducted in secondary schools of Latvia and Lithuania showed that there isn't implemented any certain strategy on how to assist young specialists at the beginning of their career in both countries. The opinion and problems faced by both groups of the respondents are more or less similar. The current research has not been focused on the comparison of the situation in Latvia and Lithuania. It was sought to highlight the tendencies in both countries providing empiric data analysis instead.

2. The research disclosed differences in the opinion considering career development between various groups of respondents. Young specialists emphasized the importance of professional preparation and while teachers- 
methodologists put an accent on personal qualities, such as persistence, willpower, self-confidence, initiative, responsibility, dutifulness, and flexibility.

3. Research results prove that success in career depends on planning, lifelong learning and qualification improvement. The attention was turned on the importance of encouragement and support from superior organizations.

4. School heads named several important factors crucial for pedagogic career, eminent among them were ability to analyze pedagogic activity, ability to take right decisions, organizational skills and class management skills, ability to construct cooperative relations.

5. On the basis of empirical evidence we may presuppose, that opportunities for career in secondary schools are average. Young specialists consider it as the result of today's school environment, insufficient assistance from experienced colleagues and school heads side. According to school heads' and teachers-methodologists' opinion, young specialists are unable to enjoy the career opportunities through their own fault.

6. All the respondents were common in their opinion about the importance of school heads role in the teachers' career development. The data analyzed gives a basis to state, that school principal should be responsible for creating conditions for successful teachers', and especially young specialists' career development. Principal should support and encourage young specialists 'initiatives. It is of a special importance to provide opportunities for young specialists to acquire work experience, self-assurance, assist in overcoming obstacles and provide possibilities to develop professionally and personally.

7. The research results show that young specialists feel the lack of theoretical preparation: pedagogy and psychology knowledge, practical experience. High schools students as future pedagogues should have an opportunity to get acquainted with class masters responsibilities and learn how to organize after-classes activities. Moreover, it would be useful to extend the terms of pedagogical practice and provide high-qualified assistance during the practice.

\section{References}

Gumuliauskienė, V., Augienė, D. et al. (2002). Karjera šiandien ir rytoj. Šiauliai: ŠU leidykla. Jucevičienè, P. (1996). Organizacijos elgsena. Kaunas: Technologija.

Jucevičienè, P., \& Lepaitè, D. (2000). Asmeninès karjeros valdymo gebejjimai ir jų ugdymo gairès. Profesinis rengimas. Tyrimai ir realijos, Nr.6, p. 15-26.

Petkevičiūtè, N. (2003). Asmeninès karjeros projektavimas ir vystymas globalizacijos kontekste. Profesinis rengimas. Tyrimai ir realijos, Nr.6, p. 13-21.

Stanišauskienè, V., \& Večkienè, N. ( 1999). Karjeros samprata: mokslinio požiūrio kaita ir jos refleksijos Lietuvoje problema. Socialiniai mokslai, Nr.2, p. 23-30. 
Julija Melnikova, Jel̦ena Zaščerinska. The Conditions and Opportunities for Teachers' Professional Adaptation and Career in Schools of Latvia and Lithuania

Olehnovica, E, \& Kravale-Paulina, M. (2008). Career education for teachers: reflections on ESF Project implementation in Latvia. Journal of Teacher Education for Sustainability, Nr. 9 (1), p. 68-80. 